of the pituitary fossa in $80-90 \%$ of patients ${ }^{45}$ and tomography will show enlargement or asymmetry in nearly all the remaining cases. ${ }^{5}$ The assessment of visual fields by perimetry and of the extent of the lesion by air encephalography are mandatory. Tests of the effects of an expanding intrasellar lesion on other pituitary functions complete the pretreatment work-up.

The objectives of active treatment for acromegaly are consistent reduction in G.H. secretion and relief of local pressure effects in the area of the pituitary fossa. There is general agreement that patients with extensive suprasellar spread of the tumour need surgery, particularly if there is a major visual field defect. Additional treatment by external radiotherapy may be required after surgical intervention. Minor field defects and small suprasellar extensions may be treated satisfactorily by those methods of treatment used in the patient with a purely intrasellar tumour.

The main methods of destructive treatment for intrasellar lesions are external irradiation, interstitial irradiation, proton beam therapy, transsphenoidal hypophysectomy, and cryosurgery. External irradiation is often considered relatively ineffective, ${ }^{6} 7$ though reported response rates vary. Interstitial irradiation (using yttrium-90) is widely practised, and a satisfactory clinical response is seen in more than $50 \%$ of patients. ${ }^{8}$ This method may be complicated by pituitary failure $(25 \%)$, cerebrospinal rhinorrhoea $(13 \%)$, or local infection $(12 \%)$, and it is suitable only when the tumour is of regular shape and has not eroded adjacent structures. Two groups of patients ${ }^{9} 10$ treated by proton beam therapy (which is not available in Britain) have been reported to show a satisfactory response, but close examination of the data suggests no distinct advantage for this form of treatment. Cryosurgery has been carried out in small groups of patients, but in some series the complication rate has been unacceptably high without being offset by a clear therapeutic advantage. The transsphenoidal approach to a pituitary tumour has been in use since the early years of this century. Clinical and biochemical improvement can be expected in more than $80 \%$ of cases, ${ }^{13-15}$ and the method has the major advantage that most or occasionally all of the G.H. secreting tissue is cleared immediately. The disadvantages are a higher incidence of hypopituitarism, the risk of cerebrospinal rhinorrhoea $(2-10 \%)$, and occasional cases of meningitis.

Each of these methods of treatment has its supporters. The lack of any satisfactory comparative studies has meant that the choice has depended as much as anything on where the patient presented with acromegaly. Probably either transsphenoidal hypophysectomy or interstitial irradiation are the most effective methods of treatment, but no method is ideal, and a good prospective study of the merits of these various techniques is required.

Two recent developments have raised the possibility of medical treatment for acromegaly. The hypothalamic growth hormone release inhibiting hormone (G.H.R.I.H.) effectively lowers G.H. levels in acromegaly though its duration of action is short, parenteral administration is required, ${ }^{16}$ and it does have major effects on pancreatic function. ${ }^{17}$ The ergot alkaloid 2 - $\mathrm{Br}-\alpha$-ergocryptine is known to be effective in reducing plasma prolactin levels and it also reduces G.H. levels in acromegalic subjects. ${ }^{18}$ This substance is active orally and preliminary studies suggest a duration of action of three to four hours. Either G.H.R.I.H. in a suitable long acting form or ergocryptine when more fully assessed might have considerable therapeutic potential, for medical treatment would not interfere with other essential pituitary functions.
1 Wright, A. D., et al., Quarterly fournal of Medicine, 1970, 39, 1.

2 Hartog, M., Gaafar, M. A., and Fraser, R., Lancet, 1964, 2, 376.

3 Kanis, J. A., et al., Quarterly fournal of Medicine, 1974, 43, 409.

Lang, E. K., and Bessler, W. T., American fournal of Roentgenology, 1961

86, 321.
5 LLachlan, M. S. F., Wright, A. D., and Doyle, F. H., British fournal of

Radiology, 1970, 43, 360.
6 Pearson, O. H., Kaufman, B., and Brodkey, J., New England fournal of Medicine, 1970, 283, 999.

7 Jenkins, J. S., Ash, S., and Bloom, H. J. G.,Quarterly Fournal of Medicine, $1972,41,57$

${ }^{8}$ Wright, A. D., et al., Proceedings of the Royal Society of Medicine, 1970, $63,221$.

${ }^{\circ}$ Kjellberg, R. N., et al., New England Fournal of Medicine, 1968, 278, 689.

10 Lawrence, J. H., et al., Fournal of Clinical Endocrinology, 1970, 31, 180.

11 Adams, J. E., et al., fournal of Neurosurgery, 1968, 28, 100.

12 Cross, J. N., et al., Lancet, 1972, 1, 215.

13 Williams, R. A., Proceedings of the Royal Society of Medicine, 1974, 67, 881. 14 Dalton, G., Proceedings of the Royal Society of Medicine, 1974, 67, 885.

${ }_{15}$ Richards, S. H., Thomas, J. P., and Kilby, D., Proceedings of the Royal Society of Medicine, 1974, 67, 889.

${ }^{16}$ Hall, R., et al., Lancet, 1973, 2, 581.

17 Alberti, K. G. M. M., et al., Lancet, 1973, 2, 1299.

${ }^{18}$ Liuzzi, A., et al., fournal of Clinical Endocrinology, 1974, 38, 910.

\section{Is Salmon a Scapegoat?}

Asked for their views on present-day nursing, doctors often blame the Salmon ${ }^{1}$ structure for the apparent decline in the quality of nursing care in hospitals. They attribute the serious shortage of experienced nursing staff on the wards to the lack of any career prospects for senior nurses except in the administrative grades at the top of the Salmon ladder. This view is shared by many nurses too-as became plain at a joint meeting of the Royal Colleges of Nursing, Midwives, Obstetricians and Gynaecologists, Physicians, and Surgeons held at the Royal College of Physicians in London last week.

Yet doctors who look back with nostalgia to the time when a faithful sister spent most of her waking hours on the ward, year after year, may be being unrealistic if they think Salmon is to blame for her disappearance. Changes have occurred in society and in the attitudes of young women, most of whom now look on nursing as a professional occupation and not as a vocation. In common with their contemporaries in other jobs (including medicine) they want reasonable hours of work, proper off-duty, and adequate pay. The days of the dedicated spinster have gone for ever.

This change in attitudes has been accompanied by an alteration in the balance of trained and untrained nurses in hospitals. Between 1968 and 1972, the conference was told, the numbers of qualified nurses rose by $14.5 \%$ but the numbers of other nursing staff (including those in training) rose by $45 \%$ in the same period. Such a dilution of experienced nurses has a direct effect on the quality of nursing care. Perhaps, as several speakers suggested, marriage and other attractions outside nursing take away more ward sisters than Salmon-though the recent Halsbury pay award ${ }^{1}$ may check this trend.

The second half of the conference provided some welcome optimism for the future. Specialist nurses, so long a feature of North American practice, are growing in numbers in the N.H.S. Many more nurses are going on courses of training in special fields such as liver and kidney disease and neonatal care. A recent trend in medicine has been the recognition of the value of clinical teams in which these nurses can play a vital role, and the specialist nurses at the conference stressed the satisfaction that they got from their work in such teams.

At present, however, even fully-trained specialist nurses often have to make considerable financial sacrifices in order to obtain this job-satisfaction. Some of them are graded as nursing officers, but many are not. Specialist nursing could 
provide the pathway so clearly needed for nurses who want to follow a clinical career, but the work must be recognized as carrying at least equal status and equal pay to administration. Such was certainly the intention of Mr Brian Salmon himself: he had no doubt, he told the conference, that highly trained clinical nurses should stay on the ward and be properly rewarded for doing so.

${ }^{1}$ Report of the Committee of Inquiry into the Pay and Related Conditions of Service of Nurses and Midwives. London, H.M.S.O., 1974.

${ }^{2}$ Report of the Committee on Senior Nursing Staff Structure, (Chairman Mr. Brian Salmon). London, H.M.S.O., 1966.

\section{Getting it Right}

Two aspects of modern medical practice have given added impetus to current studies of clinical decision-making and its consequences. One is the growing awareness that while demand for medical care is open-ended the resources for its provision are finite, so that those who provide such care should make the best possible use of these limited resources. Second is the development (painfully, incompletely, and belatedly) of a "new" mathematical framework with which to handle the problems which arise in applying decision-theory to medical practice. These aspects, in fact, are closely linked and practical solutions could help a sorely pressed Health Service" - a feature that made last week's conference on "The doctor as a clinical decision-maker" at the Royal College of Physicians particularly timely.

In the past many of the difficulties in this area have been the fault of the theorists themselves; for, while the medical profession has an enviable reputation in adopting new methods and techniques, the individual doctor must see some relevance in a new system if he is to support it whole-heartedly. Sad to say, many of the early efforts in medical decision-making either ignored medical facts and opinions or were so wildly impractical that they in turn were ignored by the medical profession altogether. Indeed, enormous harm has already been done in the biological sciences by individuals (largely computer-oriented) promising the moon and failing to deliver anything of substance at all.

More recently, however, application of information science and decision-making theory seems to have reached the stage where (at last) some practical benefit to the patient is emerging. To take a few examples which were presented at the conference, research at the Liver Unit at King's College Hospital has redefined the role of laboratory tests in jaundice; Jennett's studies in Glasgow ${ }^{2}$ have provided the clinician with a much clearer picture on which to base his decisions after head injury; the Leeds system ${ }^{3}$ appears significantly to improve the quality of clinicians' decision-making in diagnosis of the acute abdomen; and, most recently of all, Emerson et al. ${ }^{4}$ have applied decision-theory to the problem of deep-vein thrombosis after myocardial infarction.

This last report presents an elegant and topical study in decision-making. Death from pulmonary embolism after myocardial infarction can be prevented by prophylactic therapy-but this therapy itself may result in death from bleeding due to the administration of the drug. What Emerson et al. have done is to evaluate the situation using decisiontheory and they then drew up a set of treatment allocation rules (based on such simple attributes as the patient's age and smoking habits). Moreover, in a prospective validation these rules have shown how to cut the death rate from pulmonary embolism or its treatment by about one-third.
Quite clearly, in all of these areas a great deal more work remains to be done in order to assess more fully the nature and extent of any possible benefits and to determine which systems can achieve these benefits most simply and cheaply. Equally clearly the role of mathematics will vary from application to application. Once the initial calculations have been carried out, Emerson and his colleagues have produced a system which can be followed by anyone using the back of an envelope. In other situations, such as the Leeds system, some form of computer assistance seems necessary, though at Leeds reformulation of the system made it suitable for an extremely small desk-top computer. ${ }^{5}$

So for the first time the theory of information science and decision-making is beginning to show some practical benefit in clinical medicine. The role which this new discipline will have in the future is far from certain at this stage; but as special investigations and complex treatments become more and more expensive in terms of time and money it may well be many traditional values and practices will need a fresh reexamination. For that to happen, however, the new mathematics will have to become very down to earth, and its practitioners will have to develop an empathy with the medical profession which has not always existed in the past. To that end, the recent series of practical studies and the R.C.P. conference are to be welcomed.

\footnotetext{
1 British Medical fournal, 1974, 4, 272, 327, 389.

Jennett, B., Teather, D., and Bennie, Susan, Lancet, 1973, 2, 652

de Dombal, F. T., et al., British Medical fournal, 1974, 1, 376

4 Emerson, P. A., Teather, D., and Handley, A. J., Quarterly fournal of Medicine, 1974, 43, 389.

${ }^{5}$ Horrocks, Jane C., Methods of Information in Medicine, 1974, 13, 83.
}

\section{Allergy to Corticosteroids}

Apparently any drug can cause allergic or idiosyncratic reactions in man. Corticosteroids are often used in treating these complications, so it is perhaps surprising that they themselves may provoke anaphylactic responses. But Mendelson et al. ${ }^{1}$ have recently reported the case of a young asthmatic who rapidly developed urticaria, angioneurotic oedema, and increased bronchospasm after intravenous injection of methylprednisolone or hydrocortisone.

The drugs had been prescribed in proprietary preparations (Solu-Medrone and Solu-Cortef) so that much careful detective work had to be done before the culprits could be identified. Solu-Medrone contains methylprednisolone sodium succinate in a diluent which contains many preservatives including methylparaben and propylparaben, which are known skin-sensitizing agents. ${ }^{2} 3$ Intradermal skin tests using Solu-Medrone or Solu-Cortef gave negative results up to 48 hours, so it was decided to test the effect on the patient of Solu-Medrone under supervision in hospital. Initially $4 \mathrm{mg}$ of the preparation was injected intravenously, and the patient experienced no untoward symptoms during the subsequent hour. However when $40 \mathrm{mg}$ of the drug was given intravenously he developed urticaria, angioneurotic oedema, and severe bronchospasm. An intravenous test-dose with the diluent alone caused no untoward reaction. To evaluate the effect of sodium succinate $40 \mathrm{mg}$ of plain methylprednisolone was given orally, and thirty minutes later he developed the reaction as before.

Later, tests with $40 \mathrm{mg}$ of prednisone or prednisolone and $6 \mathrm{mg}$ of dexamethasone produced no abnormal symptoms. The intradermal skin tests were repeated using methylprednisolone and hydrocortisone tablets or powder with 